\title{
UMA ANÁLISE COMPARATIVA DOS CONCEITOS DE SUBALTERNIDADE E RACIALIDADE ${ }^{1}$
}

\author{
Lucas Trindade da Silva ${ }^{2}$
}

RESUMO: Pretendo refletir em que medida a crítica de Vivek Chibber aos estudos subalternos indianos é válida para pensar as contribuições teóricas do sociólogo peruano Aníbal Quijano. Uma questão será fundamental para pensar a fase dita decolonial de Quijano: Tal qual os estudos subalternos, Quijano propõe uma explicação sobre a singularidade do desenvolvimento capitalista na periferia, para os indianos a subalternidade é conceito central para entender a Índia colonial e pós-Independência, para Quijano a racialidade é crucial para entender o capitalismo latino-americano e a formação dos Estados nesta região, quais as afinidades e diferenças entre os dois conceitos?

PALAVRAS-CHAVE: Subalternidade, Racialidade, Capitalismo.

\begin{abstract}
I intend to reflect to what extent the criticism of Vivek Chibber to the Indian subaltern studies is valid to consider the theoretical contributions of the Peruvian sociologist Anibal Quijano. One issue will be critical to think the called decolonial phase of Quijano: Just like the subaltern studies, Quijano proposes an explanation of the singularity of capitalist development in the periphery, for subalternists subalternity is a central concept to understand colonial and post-Independence India, for Quijano raciality is crucial to understand Latin
\end{abstract}

1 Uma primeira apresentação das questões discutidas nesse trabalho foi realizada no espaço do SPG. Teoria social no limite. Novas frentes/fronteiras na teoria social contemporânea na ocasião do $38^{\circ}$ Encontro Anual da Anpocs sob o título "Pensamento pós-coloniall decolonial e capitalismo periférico: Aníbal Quijano diante dos Subaltern Studies, confluências e contrastes". Registro aqui o agradecimento aos professores Sergio Tavolaro e Artur Perrusi pelas críticas valiosas e fundamentais para o desenvolvimento do presente artigo.

${ }^{2}$ Doutorando do Programa de Pós-Graduação em Sociologia, vinculado ao Instituto de Ciências Sociais da Universidade de Brasília, localizado no Campus Universitário Darcy Ribeiro/UnB. 
American capitalism and the formation of States in this region, what are the similarities and differences between the two concepts?

KEYWORDS: Subalternity, Raciality, Capitalism.

\section{INTRODUÇÃO}

Podemos remontar as raízes do que hoje é agrupado sob a denominação de pensamento pós-colonial/decolonial, embora ainda sem ismos classificatórios, a trabalhos publicados no imediato pós II Guerra Mundial. Ballestrin (2013) nos fala mesmo de uma "tríade francesa" como os clássicos do pós-colonialismo, cronologicamente: Retrato do Colonizado Precedido de Retrato do Colonizador (1947), de Albert Memmi; Discurso sobre o Colonialismo (1950), de Aimé Césaire; Os Condenados da Terra (1961), de Frantz Fanon. Agregado a esta tríade, Ballestrin (Ibid.) canoniza Orientalismo (1978), de Edward Said.

Quatro anos depois, em 1982, forma-se, por iniciativa de um conjunto de intelectuais indianos inseridos em academias do mundo anglosaxão, o Subaltern Studies, cujo propósito inicial, evidenciado no prefácio ao primeiro volume do periódico anuário e homônimo do grupo, era "não só de descobrir a história das classes trabalhadores do Subcontinente, mas também de fornecer alguma explicação para o fracasso histórico do nacionalismo indiano, seja como um projeto de elite ou uma aspiração popular por uma luta de libertação nacional" (Chibber, 2013: 6).

Dez anos depois da formação do Subaltern Studies indiano, em 1992, quando o texto Colonialidad y Modernidad-Racionalidad de Aníbal Quijano é reimpresso, forma-se, nos Estados Unidos, o Grupo Latino-Americano de Estudos Subalternos, também constituído majoritariamente por intelectuais do Sul com ampla inserção no mundo acadêmico anglo-saxão, e cujo "founding statement... foi originalmente publicado em 1993 na revista Boundary 2, editada pela Duke University Press" (Ibid.: 94). Esse texto de fundação só será traduzido para o espanhol em 1998, com o título de Manifesto Inangural del Grupo Latinoamericano de Estudios Subalternos, inserindo assim a América Latina "no debate pós-colonial". 
No mesmo ano de tradução do Manifesto Inaugural, o Subaltern Studies latino-americano se desagrega. Além do juízo sobre a permanência de elementos eurocêntricos nos subalternistas indianos (influências desconstrutivistas e pós-estruturalistas), a crítica latino-americana, liderada por Walter Mignolo, defendia a elaboração de conceitos intrinsecamente ligados ao contexto diferenciado da América Latina, evitando toda transposição de conceitos elaborados alhures.

A ala latino-americana crítica ao subalternismo indiano formará então o Grupo Modernidade/Colonialidade. "Ainda no ano de 1998, um importante encontro apoiado pela CLACSO e realizado na Universidade Central da Venezuela, reuniu pela primeira vez Edgardo Lander, Arthuro Escobar, Walter Mignolo, Enrique Dussel, Aníbal Quijano e Fernando Coronil" (Ibid.: 97). No mesmo ano, em Binghamton, vários desses autores se encontrarão novamente, contando também com a presença de Immanuel Wallerstein. Podemos perceber assim a confluência de contribuições teóricas diversas e originais (Ibid.: 98), como a teoria da dependência (Quijano), a filosofia da libertação (Dussel), a teoria do sistema-mundo (Wallerstein).

Mignolo (apud Ballestrin, 2013: 108), além de entusiasta da desagregação do Grupo Latino-Americano dos Estudos Subalternos, é quem propõe a distinção entre o "projeto des-colonial" ou decolonial latino-americano - sendo a decolonialidade o terceiro termo que se afirma a partir da negação do par inseparável modernidade/colonialidade - e o "projeto pós-colonial" indiano. Distinção esta que mais uma vez evidencia a importância crucial de Aníbal Quijano no debate, sobretudo o conceito de colonialidade do poder/saber, "amplamente utilizado pelo grupo" (Ibid.: 99).

No par modernidade/colonialidade está implicado um projeto muito mais amplo do que a história nacional a contrapelo dos subalternistas indianos. Para Quijano (1992; 2005; 2014), Europa/América, Modernidade/Colonialidade (Racialidade) têm como marco de fundação recíproca e simultânea o ano de 1492. A América Latina é colocada como o mirante privilegiado para uma história a contrapelo global. 
O interesse aqui é o de se inserir no debate sobre a diferença decolonialidade/pós-colonialidade através de uma análise teórica comparativa dos conceitos de subalternidade e racialidade, atentando para as suas diferenças e semelhanças, assim como para as consequências destes conceitos numa reflexão sobre o capitalismo (central e periférico). Tomarei como ponto de partida a crítica de Vivek Chibber (2013) aos Subaltern Studies, pela sua tentativa de sistematização abrangente de autores fundamentais deste grupo. Feito este trabalho, poderei abordar a obra de Aníbal Quijano. O objetivo é o de testar a validade do programa crítico de Chibber na análise dos conceitos quijanianos.

\section{SUBALTERNIDADE}

Vivek Chibber (2013), no seu Postcolonial Theory and The Specter of Capital, se propõe o desafio de realizar uma crítica da teoria pós-colonial, a despeito da diversidade dos seus teóricos, da polissemia da própria expressão, e do seu caráter fragmentário e mesmo contraditório caso os marcos literários principais sejam tomados como um conjunto. De modo a contornar tais dificuldades, Chibber elabora uma estratégia críticoanalítica engenhosa. Segundo ele, os Subaltern Studies, se tomados como "teoria", têm como base fundamental uma explicação para a singularidade do capitalismo periférico indiano, presente e explícita, sobretudo nos textos de Ranajit Guha (1982; 1997) e Dipesh Chakrabarty (2000). Esta explicação se desenvolve de forma contrastiva em relação a uma suposta "história convencional" ou narrativa clássica sobre o desenvolvimento capitalista nos países centrais (Inglaterra e França). É nesse suposto núcleo duro que, para Chibber, nós encontraremos elementos, senão constantes e presentes, ao menos influentes de forma determinante nos argumentos de amplo espectro do pensamento pós-colonial.

Por "história convencional" (Chibber, 2013: 12) se entende a história da modernidade e do capitalismo contada, sobretudo por teóricos liberais (mas também por teóricos da modernização e marxistas), onde se estabelece uma relação necessária entre "universalização do capital" no nível econômico e transformações político-culturais de perfil democrático. 
Para Guha (1997) - Dominance Without Hegemony - e Chakrabarty (2000) - Provincializing Europe -, que sintetizam esse debate, se a história convencional é válida para países como França e Inglaterra, onde a burguesia teria estabelecido uma aliança hegemônica com os segmentos populares, vinculando num sentido forte revolução econômica (capitalista) e revolução política-cultural (democrática), tal modelo é inteiramente falacioso quando aplicado à análise do desenvolvimento capitalista e da independência política indiana. Sobretudo para estes autores, que viveram, durante a década de 1970, um dos momentos de mais aprofundada crise do Estado indiano desde a Independência em 1947: fragmentação do Indian National Congress (INC); segunda guerra com o Paquistão (1971); greves com adesão de mais de um milhão de trabalhadores; estado de emergência entre 1975-76 (corte de liberdades constitucionais e repressão); fome para os trabalhadores; ações camponesas em West Bengal e Andhra Pradesh; o INC perde as eleições em 1977 (Ibid.: 30).

Tal atmosfera de derrota do nacionalismo indiano pode ser pensada como a base sociológica fundamental para um projeto teórico de investigação dos fatores determinantes do fracasso do INC e do seu objetivo de criação de um Estado-nação indiano forte e coeso (Ibid.: 31). Como a própria expressão - Dominance Without Hegemony ${ }^{3}$ - evidencia, a resposta para a falha do nacionalismo indiano estaria, para Guha, na inexistência de uma dominância hegemônica, de uma aliança real entre a burguesia e o povo, de um vínculo entre modernização econômica

${ }^{3}$ Guha (1997), num primeiro momento de Dominance without Hegemony, de alguma forma reconhece que, na própria Europa, a revolução alemã de 1848 representa uma descontinuidade, uma variante não-universalisante de revolução burguesa, se comparada com as revoluções inglesa e francesa. Isto ele o faz citando o Marx da Gazeta Renana (Guha, 1997: 17-18). O intrigante é que, no decorrer do texto, ele abandonará esse argumento sobre o caráter não intrínseco da hegemonia nas revoluções europeias, reiterando o dualismo revolução hegemônica no OesteNorte/revolução não-hegemônica no Leste-Sul: "How come that India universalism failed to generate a hegemonic ruling culture like what it had done at home? [...] As an anachronism, this was in agreement with the paradox of an advanced bourgeois culture regressing from its universalist drive to a compromise with precapitalist particularism under colonial conditions of its own creation. [...] bourgeois culture hits an insuperable limit in colonialism" (Ibid.: 64-5, itálico meu). Será também esta a versão que ganhará força a posteriori: “As Ranajit Guha... observes, the universalising project of bourgeois culture reached its limit in colonialism” (Connell, 2007: 16). 
e modernização político-cultural, em suma, na assimetria radical da experiência de modernização capitalista periférica indiana em relação ao modelo europeu. A burguesia indiana se mostrou, na crise pós-colonial, incapaz de falar pela nação, falhou em "integrar a cultura dos grupos díspares na sociedade indiana em uma comunidade política abrangente" (Ibid.: 33). A causa fundamental desta falha estaria na cisão entre a elite (concentrada no INC) - não completamente secularizada, aliada a forças retrógradas do período colonial (Ibid.: 47), democrática no discurso, mas orientada por uma tática política vertical-patronal - e os grupos subalternos - orientados principalmente por valores tradicionais e comunitários, inclusive em suas manifestações insurgentes.

Enquanto as burguesias francesa e inglesa ("liberalismo heroico") teriam constituído de forma bem sucedida o Estado-nação por meio do consenso, a burguesia indiana ("liberalismo medíocre"), além de fazer uso permanente da coerção (formas coloniais de exercício de poder) como instrumento de reprodução do seu domínio político, foi também incapaz, justamente pelo seu caráter não-hegemônico, de consolidar o Estadonação indiano.

Temos então como fundamentos do projeto de descontinuidade epistêmica pós-colonial: 1) um argumento histórico - a diferença radical entre as experiências de modernização capitalista central e periférica; 2) um argumento sociológico - o caráter distinto das hierarquias sociais nessas duas experiências, a dimensão tradicionalista e comunitarista dos segmentos subalternos indianos (o que confere relativa autonomia em relação às elites), ao contrário da unificação valorativa secular percebida nos casos centrais; 3) um argumento político - o caráter consensuale pacífico das relações entre classes nos países centrais em oposição ao caráter coercitivo/arbitrário/patriarcal das relações entre elites e subalternos na Índia periférica.

Chakrabarty (1989) no seu Rethinking Working Class History: Bengal 1890-1940, reafirma a tese da dominância sem hegemonia, e a tese da subalternidade como sintoma do caráter não-universalizante do capital, dando particular ênfase à "falha" do capital em adquirir supremacia ao "transformar as relações de poder" (Chibber, 2013: 103) na variante 
não-universalista de capitalismo indiana. Diante desta falha, o poder, sobretudo nas relações de trabalho, não se apresentaria sob suas "formas burguesas", haveria "capitalismo, mas sem hierarquias capitalistas, dominação capitalista sem uma cultura capitalista hegemônica" (Chakrabarty apud Chibber, 2013: 105). Tal forma não-burguesa de exercício do poder define o conceito de dominação "paternal", que se legitima na relação entre gerentes e trabalhadores como "justiça paternal", marcadamente distinta das relações de exploração capitalistas, nas quais, para Chakrabarty, formas coercitivas e diretas de dominação teriam sido completamente eliminadas.

Chatterjee, por sua vez, "nega", escreve Chibber (2013: 153), a existência de um "conjunto de necessidades e interesses" compartilhados por agentes de culturas distintas,

argumentando, ao contrário, que camponeses e trabalhadores industriais no Leste têm uma psicologia inteiramente diferente daqueles no Oeste. No Oeste, nos é dito, a psicologia política gira em torno de concepções seculares do indivíduo e seus direitos; enquanto no Leste, a agência é motivada pelo conceito de dever, ou obrigação, tornando a orientação básica do ator religiosa, e não secular (Chibber, 2013: 153, tradução livre).

Teríamos então, como derivação direta daquela falha estrutural que distingue a dominância hegemônica ocidental e a dominância sem hegemonia oriental (e estabelece para esta um corte abrupto entre elites e subalternidade), a dualidade entre o princípio do interesse como orientação fundamental da ação no Ocidente, e o princípio de comunidade como orientação central das mobilizações políticas subalternas no Oriente.

Assim, a subalternidade é um domínio constituído como resultado da falha estrutural da burguesia indiana em estabelecer uma dominância hegemônica e universalizar valores seculares e democráticos supostamente vinculados, de forma necessária, ao desenvolvimento capitalista. Se, diante desta falha, as elites assumem um caráter conservador, aliando-se a forças mantenedoras do status quo ante colonial, a subalternidade mantém-se 
completamente imersa num universo tradicionalista e religioso, opressor do desenvolvimento de valores de interesse e individualidade, articulando sua potência ativa e insurgente a partir de bases predominantemente nãoseculares. Quando se encontram - elite e subalternidade - no mundo do trabalho, são as hierarquias tradicionais que terão preeminência, a exploração (capital) da força de trabalho através de formas coercitivas de dominação (poder), diretas e interpessoais, são então legitimadas por uma cultura tradicionalista.

\section{A CRÍTICA DE VIVEK CHIBBER}

Chibber se insurgirá contra todos os dualismos que são base da descontinuidade Oeste $\mathrm{x}$ Leste subalternista: a) dominância hegemônica $x$ dominância sem hegemonia; b) relações consensuais $\times$ relações coercitivas; c) princípio do interesse x princípio da comunidade.

A) O primeiro dualismo, dominância hegemônica europeia (francesa e inglesa) x dominância sem hegemonia (indiana), é criticada através de uma revisão da historiografia recente, principalmente os trabalhos de Robert Brenner (1985; 1993), sobre as revoluções inglesa e francesa. O que Chibber deslegitima não é a leitura subalternista sobre a ausência de estratégia hegemônica e de valores democráticos da burguesia indiana. Pelo contrário, esta leitura está parcialmente correta, o erro está na interpretação romantizada dos eventos revolucionários que ocorreram no velho continente. Ironicamente, tal romantização destes eventos revolucionários, reproduzida por Guha, lança suas raízes na historiografia francesa da época da queda de Napoleão (Thierry, Guizot, Mignet, SaintSimon), e na historiografia Whig inglesa, ala mais conservadora, oposta aos Tory, no espectro político da Inglaterra oitocentista (Chibber, 2013: 93-7). Historiografia que teve influência inclusive sobre o pensamento de Marx, que atesta certa ambiguidade ao abordar as revoluções burguesas.

Segundo a versão romântica, a revolução inglesa representa a vitória apoteótica de um Parlamento (House of Commons) burguês, liderado por Cromwell, sobre o monarca Charles I dos Stuart, representante das forças feudais. Só a partir deste fiat, que tem como marco 1649, teria havido 
uma liberação de forças genuinamente capitalistas na Inglaterra, sendo esta, grosso modo, a narrativa reproduzida por Guha. Chibber (Ibid.: 56-66) argumentará, no entanto que, já em 1640, as relações agrárias na Inglaterra haviam mudado a tal ponto que já não se podia falar em relações feudais. A revolta de certos detentores de terra (a ala revolucionária) foi, sobretudo, contra o absolutismo (ordem política) e não contra um suposto feudalismo (ordem econômica).

No período dos Tudor, que vai até o início do século XVII, onde surge a figura do Bailiff ou tenant - "arrendatário capitalista" (Marx, 2008, 857 ) - os donos de terra conseguiram certa estabilidade, num sistema de predomínio dos poderes locais. No entanto, esse sistema, embora próspero produtivamente, deixava a Inglaterra atrás de outros Estados em termos de monopolização e acumulação fiscal, particularmente a França. Foi exatamente essa monopolização que os Stuart tentaram realizar, e foi contra isto que os lords, através do Parlamento, se insurgiram.

Sem ter estes elementos em mente, e fiel à concepção anti-feudal - e não anti-absolutista - da revolução de Cromwell, Guha avança na ideia de que o parlamento desenvolveu um projeto hegemônico, capaz de aglutinar o campesinato e as classes trabalhadoras urbanas em torno da luta contra as relações feudais e pela generalização de direitos políticos para as classes subordinadas. Contra isto, Chibber nos diz que a intenção original do parlamento foi elitista, buscava precisamente retornar a uma ordem política descentralizada, subordinando Charles I à mesma. É só por volta de 1642, com os rumores de uma coalizão militar por parte de Charles I, que o Parlamento buscará apoio popular, não por um espírito hegemônico democrático, mas por razões puramente estratégicas. A mobilização política das massas, no entanto, não podia ser inteiramente controlada pelos interesses dominantes. Logo o perigo potencial de uma verdadeira rebelião de massas se apresentou no horizonte, fazendo com que boa parte da liderança parlamentar assumisse uma posição conservadora ou neutra diante da iminência de guerra civil. Boa parte do Parlamento viu-se acuada entre a rebelião popular e a repressão monárquica.

Distante do mito da burguesia heroica, o que o parlamento desejava "era um pacto de elite" (Ibid.: 62). Essa orientação estratégica, visando 
"garantir que as classes populares [fossem] mantidas fora do novo conceito de nação" (Ibid.: 64), se manteve após 1649. A garantia mais abrangente de direitos só virá em 1689, com a Bill of Rights, período de abertura política novamente interrompido com o caráter autocrático da era georgiana.

Diferente da Inglaterra, onde relações de tipo capitalista já eram predominantes antes da revolução, a França setecentista de fato estava imersa no feudalismo. Guha portanto está correto em enfatizar o caráter anti-feudal da revolução de 1789, o problema está, mais uma vez, no mito da burguesia hegemônica.

Nesse contexto o que prevalece é a velha lei do "quem não sobe, cai" (Elias, 1993: 134). Se no século XVII era a Inglaterra que entrava em convulsão diante do poderio do Estado francês, que foi capaz de consolidar o processo de monopolização fiscal-militar. No século XVIII, era uma França em crise fiscal - a arrecadação minguava diante do conservadorismo das relações feudais e dos privilégios da nobreza que entrava em convulsão diante da favorável situação econômica da sua maior rival, a Inglaterra. Luís XVI (Chibber, 2013: 66-76), consciente desta situação, busca uma solução conciliatória que imediatamente se mostra impossível. Se a necessidade de desmantelar o absolutismo dos Bourbon era clara para os delegados componentes do Estado-geral reunidos em 1789, como fazer isso não era.

Fundamental reter que: 1) neste momento, nenhum dos delegados se insurgiu num chamado à revolução, a proposta de uma monarquia constitucional era a mais radical; 2) o terceiro estado não "mostrou qualquer compromisso ex ante com a soberania popular. [...] [R]eforma, portanto, significa[va] maior alcance político e social para si mesmos"; 3) o terceiro Estado de modo algum era composto por segmentos ligados à forma capitalista de produção - dos 610 somente 90 tinha algo a ver com comércio (pequenos burgueses), os 10 ligados a setores industriais eram setores bastante tradicionais, protegidos pelo Estado, os jacobinos, por sua vez, estavam entre os mais pobres dos delegados, "mais próximos do mundo plebeu das massas parisienses que do brilho das classes abastadas" (Ibid.: 68-9). 
No Ancién Regime, burguesia estava longe de ser um termo preciso, pertencendo a esta aqueles que não se inseriam em nenhum outro grupo positivamente definido, ou seja, era uma definição negativa: "nem camponeses nem trabalhadores, estas pessoas pertenciam aos estratos abastados fora da nobreza" (Ibid.: 69-70), sendo em sua maioria profissionais urbanos. Isto já coloca uma segunda dificuldade - além do caráter autocentrado e não-popular do terceiro estado num primeiro momento - em falar, tal qual Guha, de uma burguesia francesa hegemônica como se estivéssemos falando de um grupo fortemente coeso.

Mesmo depois de assumirem o poder, o objetivo fundamental do terceiro estado continuou sendo a dissolução da Monarquia Absolutista em favor de uma Monarquia constitucional, objetivo que foi atingido em Junho de 1789. A prova do caráter autocentrado e não-popular do terceiro estado foi a ausência de ampliação dos direitos subalternos neste momento (ver Ibid.: 71).

Logo - com os preparativos para um golpe militar - ficou claro que Louis XVI tinha feito somente uma concessão temporária à Assembleia Nacional, e foi o golpe que tornou inevitável a intervenção das massas e levou à queda da Bastilha. Isto junto a um forte movimento revolucionário rural, desencadeado pelo estoque de grãos por parte das classes proprietárias. Com a ação popular, Louis XVI se retratou e a Assembleia Nacional se reestabeleceu. Mais importante foi a radicalização do movimento provocada pelas massas, impelindo "a assembleia a medidas mais radicais" (Ibid.: 72). A apreensão das elites, que em agosto - com a abolição radical da ordem feudal e a declaração dos direitos do homem e do cidadão - tornou-se pânico, deixou então de ser com o Monarca para ser com as massas. Durante este processo de radicalização, a 'burguesia' (setores médios) tentou a todo tempo minimizar "os golpes à estrutura de poder existente" (Ibid.: 73), restringindo, por exemplo, o sufrágio universal, que só será finalmente conseguido em 1792, para novamente cair, com a substituição dos jacobinos por uma coalizão conservadora, em 1795. Só em 1848 o radicalismo político entrará de forma significativa em cena na França, o que demonstra, no mínimo, o exagero da ideia de burguesia hegemônica. 
De forma conclusiva, longe de negar o caráter revolucionário destes eventos, Chibber (Ibid.: 77-9) busca dissipar mitos. Do ponto de vista econômico, na Inglaterra o capitalismo já pré-existia e foi catalisado com a revolução; na França, a propriedade camponesa acabou sendo reforçada. Do ponto de vista político, não se pode dizer que o liberalismo político reinou hegemonicamente nessas revoluções. O efeito mais efetivo desses eventos foi desenvolver e dar robustez ao Estado (monopolização fiscal e militar), não ao capitalismo ou à democracia. " $[D]$ ominaşão sem hegemonia [...] tem sido a face normal do poder burguês" (Ibid.: 91, itálico meu).

Isto não quer dizer que o raciocínio de Guha a respeito das elites indianas esteja inteiramente correto. Embora a dominância sem hegemonia seja um fato histórico tanto no centro como na periferia, isto não se deve a atributos essenciais das elites burguesas. $\mathrm{O}$ desdobramento mais ou menos restrito/mais ou menos amplo de um processo revolucionário não tem como único determinante questões ideológicas, mas também fatores geopolíticos. Embora a narrativa de uma burguesia hegemônica e democrática não tenha sentido ao refletirmos sobre a revolução inglesa e francesa; após a segunda guerra mundial, de fato, um conjunto de países europeus e os EUA passaram por processos amplos de democratização e ampliação de direitos sociais, com a multiplicação das experiências de Welfare State, algo muito próximo da imagem de dominância hegemônica, fundada num pacto entre a burguesia e os segmentos trabalhadores populares. Na Índia, no entanto, essa experiência não foi vivida, mantendose uma enorme disparidade entre elites e subalternos.

As razões principais desta assimetria entre os fenômenos, que aqui só poderão ser tratadas de forma breve, são:

1) $O$ patamar atingido pela luta entre as classes. A experiência histórica mostra como processos de aprofundamento e ampliação nacional de direitos sempre estiveram ligados a uma maior organização das classes trabalhadoras, sendo o pacto fordista a maior evidência empírica (ver Ibid.: 147-151);

2) Questões geopolíticas ligadas à configuração da divisão internacional do trabalho e ao desenvolvimento do complexo industrialmilitar. Após a segunda guerra, um conjunto de países europeus e os 
EUA ocupavam o lugar de centros da economia capitalista mundial, devido ao desenvolvimento das forças produtivas e tecnológicas, o que significa também maior especialização e organização da força de trabalho convertidas em maior poder de barganha frente aos segmentos patronais. A Índia, neste mesmo momento, estava na periferia da economia global, com parco desenvolvimento industrial. $\mathrm{O}$ nacionalismo indiano, para além de um "liberalismo medíocre", orientou-se estrategicamente, sob pressão das, e internamente constituído pelas, classes dominantes, para o desenvolvimento militar-industrial. $\mathrm{O}$ atendimento das demandas da grande massa, muito menos organizada e com poder reivindicativo mitigado diante da preponderância das pressões vindas da elite e da enorme reserva de força de trabalho, acontecia sempre como um "mal necessário", e não num sentido estrutural de reforma (ver Ibid.: 262-277). Por isso, o perfil em grande medida autocrático do Estado nacional indiano, pela profunda desigualdade na correlação de forças elite-subalternos.

Vemos, diante destas rápidas observações, como pode ser prejudicial a abdicação de uma perspectiva global e a imputação de processos históricos a fatores unicamente ideológicos.

B) Um segundo dualismo, que é resultado direto do dualismo dominância hegemônica $x$ dominância não hegemônica, está na ideia de que as revoluções burguesas clássicas conseguiram generalizar no mundo do trabalho relações não-coercitivas, fundadas no consenso, enquanto a experiência periférica seria definida pela manutenção de formas coercitivas, diretas, interpessoais e autoritárias, legitimadas por valores tradicionais.

Mais uma vez não se trata, obviamente, de negar a selvageria do capitalismo periférico, mas de problematizar a imagem idílica do capitalismo central.

Chibber (Ibid.: 114-126) inicia o seu contra-argumento reconhecendo que um dos elementos que especificam o capitalismo em relação ao feudalismo é a venda livre, não forçada, da força de trabalho. É a nãopropriedade dos meios de produção que leva o trabalhador a 'livremente' vender a sua força de trabalho. No entanto, não deriva daí que a coerção interpessoal se torne externa à economia capitalista ou, remetendo a Chakrabarty, uma forma de poder estranha à relação-capital. O que muda é 
o "lugar" (location) dessa coerção interpessoal: no feudalismo a coerção está fora da produção - o senhor feudal obriga o servo a trabalhar para servilo, mas o processo de produção se dá na ausência daquele; no capitalismo é o próprio trabalhador que 'se obriga' (no interesse de subsistência) a produzir, na medida em que vende voluntariamente, via contrato, a sua força de trabalho, mas no processo de produção é continuamente monitorado e coagido a intensificar o trabalho no interesse patronal de elevação da produtividade.

Antes de qualquer coisa, deve-se enfatizar, o princípio que move o capital não é a universalização de valores democráticos (dominance with hegemony), mas a extensão e intensificação contínua da mercantilização, e a maximização do lucro, que implica, fundamentalmente, a extração de trabalho excedente. Se no capitalismo inglês do século XIX (ver Marx, 2008) a forma generalizada de extração do trabalho excedente era a maisvalia absoluta, conseguida, sobretudo através da extensão da jornada de trabalho; com o desenvolvimento simultâneo tanto da maquinaria como das lutas por limitação da jornada, desenvolve-se, na Europa, a forma de mais-valia relativa, baseada na intensificação do trabalho num limite dado de tempo e num grau avançado de desenvolvimento das forças produtivas.

A coerção se exerce, no centro do capitalismo, através do assédio gerencial, das ameaças de desemprego, da intensificação do trabalho, da ação patronal no sentido de criar concorrência entre os trabalhadores, no uso da violência, de demissões e represálias em caso de paralisações e greves, na maioria das vezes com a intervenção direta do Estado. A diminuição das formas coercitivas de intensificação do processo de trabalho pelo capital está relacionada com o crescimento da organização dos trabalhadores.

De todo modo, no interesse de aumento da produtividade, o capital sempre procurará estratégias para manter os trabalhadores fracos e divididos. Quando estas divisões podem ser estabelecidas ou mantidas através da instrumentalização de critérios culturais, raciais, étnicos, ou de casta, meia ponte já terá sido ultrapassada.

Assim, não há uma descontinuidade radical na sobredeterminação entre o interesse capitalista de exploração do trabalho excedente e formas 
pré-capitalistas de dominação (poder). Há sobredeterminação capital-poder. As formas de dominação existentes historicamente antes do capitalismo tornam-se estruturalmente capitalistas, na medida em que se articulam na produção do valor. Quão mais frágil a organização do trabalho, maior a incidência dessas formas de exploração/dominação.

C) Resta tratar da crítica chibberiana ao dualismo princípio do interesse I principio comunal. Num sentido mais preciso, este dualismo implica na concepção de que os segmentos subalternos indianos e sua organização política não poderiam ser tratados nos termos de uma teoria das classes sociais (Ibid.: 178). O problema da teoria tradicional (eurocêntrica e nacionalista), para Chaterjee e Chakrabarty, seria assumir como ponto de partida não a lógica interna da cultura onde foram socializados, mas as noções de necessidade e interesse. Fazer isso seria tomar como modelo a consciência burguesa, que estabelece uma clara delimitação entre o público (valores como igualdade e cidadania) e o privado (para onde é relegada a dimensão religiosa). Enquanto que, para os segmentos subalternos do leste, política e religião não estariam separados.

Contra isto, Chibber (Ibid.: 199) buscará afirmar uma concepção mínima de interesse - fundado na necessidade de preservação do bem-estar individual - que não recaia num mero utilitarismo. O intuito é o de tratar os segmentos subalternos não como autômatos da cultura tradicional, mas como indivíduos capazes de se insurgir contra a autoridade tradicional comunal quando esta, em articulação com os interesses do capital, legitima a opressão e ameaça o bem-estar físico. Se há sobredeterminação entre exploração capitalista (capital) e formas tradicionais de dominação (poder), há também sobredeterminação entre identidade comunal e identidade de classe.

Há também uma dimensão trágica no dualismo princípio do interesse $x$ princípio de comunidade, como bem nos mostra Chibber (Ibid.: 288-9). No esforço de um descontinuísmo radical em relação a categorias eurocêntricas, os subalternistas "insistem que os agentes Orientais operam com uma psicologia política inteiramente diferente daquela dos agentes Ocidentais". Imputam "ciência, racionalidade, objetividade, e atributos similares ao Oeste, ao invés de considerá-los como comuns a ambas as culturas". 
A “celebração do local, do particular... acaba justificando uma exoticização (exoticization) do Leste". Em poucas palavras, um anti-eurocentrismo e um antiuniversalismo tão radicais que se convertem em orientalismo.

\section{RACIALIDADE}

Foi justamente a agudeza da crítica chibberiana aos estudos subalternos que me motivou a testar sua pertinência num contexto diferenciado como a América Latina e o pensamento de Quijano. Afinal, seria este pensador vítima das mesmas aporias, apesar do esforço legítimo e comprometido de elaborar uma história a contrapelo?

A condição estrutural de capitalismo periférico e dependente dos contextos tratados estabelece surpreendentes paralelos nos fenômenos do pensamento. Trata-se, no caso da análise comparativa entre subalternistas indianos e Aníbal Quijano, de uma mesma motivação de base, que é tanto teórica como política.

Se, como vimos, o fracasso do nacionalismo indiano nos anos 70 é a base sociológica que motiva o projeto teórico subalternista, explicado pelo dualismo dominância hegemônica clássica/dominância sem hegemonia periférica, esta fundada no abismo existente entre elite e subalternidade. Quijano (1992, 2000, 2002, 2005, 2014d) também buscará dar conta teoricamente do fracasso dos projetos nacional-desenvolvimentistas na América Latina. Se o problema do desenvolvimento desigual e combinado era tratado em sua produção teórica pré-1990 (principalmente década de 70, ver Quijano, 2014a; 2014b, 2014c) através de um debate com a teoria da dependência; a partir dos anos 90, mais especificamente 1991 com a publicação de Colonialidady Modernidad/Racionalidad, a diferença entre o desenvolvimento central e periférico terá como eixo explicativo fundamental o problema da colonialidade do poder e da racialidade.

Veremos como essa semelhança de motivação teórica e política resultará em convergências entre os conceitos de subalternidade e racialidade, e na definição e crítica do eurocentrismo, o que não pode obnubilar as importantes diferenças. 
A centralidade da ideia de colonialidade do poder $r^{4}$ no pensamento de Quijano oculta um raciocínio contrafactual. Como se perguntasse a si mesmo: Por que os projetos nacional-desenvolvimentistas latinoamericanos fracassaram, enquanto países antes não considerados centrais, como os tigres asiáticos e os escandinavos, avançaram nos seus processos de desenvolvimento tanto econômico como político?

Tal contrafactualidade leva a isolar um elemento do contexto latino-americano (e africano), inexistente nos outros contextos, que pode então funcionar como elemento explicativo fundamental: "a questão das relações entre colonialidade do poder e desenvolvimento" (Quijano, 2014d: 205).

A colonialidade do poder - que se forma no colonialismo (pacto colonial) do século XVI e se reproduz para além dos processos de independência política formal - define a "classificação social básica" e hierárquica - pretendente a fundamentação científica no século XIX - entre os povos dominantes (metrópole) e os povos dominados (colônias) "em torno da ideia de raça" (Quijano, 2002: 13, itálico meu), enquanto conversão da diferença cultural em diferença natural - racialização arbitrária de elementos genéticos como a cor da pele e características anatômicas.

A colonialidade-racialidade do poder implica: 1) a explicitação do outro lado da modernidade; 2) a divisão racista do trabalho; 3) a colonialidade do saber. Trataremos dos dois primeiros pontos comparando com o conceito de subalternidade.

A) É necessário enfatizar, desde já, que Quijano em momento algum abdica de uma abordagem englobante dos fenômenos que trata. $\mathrm{Na}$ verdade, trata-se de tornar efetiva essa totalização contra dualismos estanques que dissociam o desenvolvimento do conjunto de elementos

\footnotetext{
${ }^{4} \mathrm{O}$ conceito de colonialidade do poder aparece sistematizado pela primeira em vez em 1991 em Colonialidad y Modernidad/Racionalidad, depois em 1992, num artigo com Wallerstein, La americanidad como concepto o las Américas en el moderno sistema-mundo. (Quijano, 2014d: 205, nota 3). Outro artigo mencionado (Ibid.: 207, nota 6), de 1993, é Poder y Cultura en América Latina. Baseamos a ideia de um raciocínio contrafactual para a emergência do conceito em artigo também de 1993 - América Latina en la Economía Mundial (Ibid.).
} 
econômicos, sociais, político-institucionais e normativos denominado modernidade europeia, dos processos violentos de exploração e dominação de outros povos a nível global. A afirmação é categórica - não há modernidade europeia sem colonialidade do poder.

"A outra face do mesmo processo de constituição e de consolidação do Estado-nação moderno era o mundo colonizado, África e Ásia, ou dependente, como a América Latina" (Ibid.: 13).

Podemos dizer que há então uma primeira diferença entre Quijano e os subalternistas: enquanto o primeiro analisa a relação global entre modernidade e colonialidade como processo de longa duração com configurações particulares ao longo do tempo; os subalternistas comparam experiências tomadas de forma independente, primeiro as revoluções inglesa e francesa e a formação "hegemônica" desses estados-nacionais nos séculos XVII e XVIII, depois, abruptamente, a formação "nãohegemônica" do estado-nacional indiano em pleno pós segunda guerra até a crise do nacionalismo indiano na década de 70 .

No entanto, esta diferença metodológica não impedirá fortes semelhanças nos resultados da empreitada explicativa.

Vimos como a modernidade-colonialidade empreende um processo de racialização dos povos dominados. Quanto mais o capitalismo se expandia, novas categorias raciais surgiam: "amarelos e azeitonados (ou oliváceos) somaram-se a brancos, índios, negros e mestiços” (Idem, 2005: 3). A classificação raciale é "o marco dentro do qual operam as outras relações sociais, de tipo classista ou estamental" (Idem, 1992: 438). "A dominação, em consequência, não se exerce só em termos de classes sociais ou de estratos socioeconômicos, mas acima de tudo em termos "étnico-raciais" (Idem, 2014d: 208). A colonialidade-racialidade produz uma "distribuição racista do trabalho" (Idem, 2005: 3, itálico meu). Tal divisão racializada do trabalho gerará uma estrutura de estratos engessada, próxima das castas: o topo ocupado pela elite branca-européia e pelas elites àquela vinculadas nas colônias; a base, para não dizer, à margem, os segmentos 'de cor', ligados ao trabalho manual precário e degradante.

Isto terá uma implicação fundamental no momento de formação dos estados nacionais europeus e latino-americanos no período que vai do 
século XVII até o século XIX. Enquanto na Europa os estados nacionais formaram-se sem a influência da dimensão racial, sendo todos os estratos de uma mesma "raça", houve uma ampla generalização e aprofundamento das instituições democráticas e da cidadania. Na América Latina, pelo contrário, os processos de independência política foram levados a cabo por elites com um sentimento de comunidade muito maior com a Europa do que com a grande maioria da população, 'de cor'. Tais segmentos foram considerados exteriores ao Estado-nação, não-cidadãos. Enquanto o nacionalismo liberal europeu se efetivou por não ter enfrentado o problema da colonialidade, o discurso nacionalista-liberal latino-americano fez de conta que o problema da colonialidade não existia, sem relacionar nacionalização (anti-colonização) a descolonialidade.

O resultado será o que Quijano (2005: 18) define como dependência histórico-estrutural: a aberrante aliança entre estado independente e colonialidade social.

Forma-se, portanto, na América Latina, o mesmo abismo entre elite e subalternidade encontrado na Índia. As causas são distintas: para os subalternistas, determinante é o "liberalismo medíocre" das elites indianas; para Quijano é a colonialidade-racialidade que produz um arranjo distinto na relação dominantes-dominados no centro e na periferia. Ambos, no entanto, padecem de um mesmo problema: negligenciam o caráter tardio do pacto capital-trabalho nos países centrais, e o papel da luta de classes e da organização dos trabalhadores no avanço dos processos de nacionalização e democratização na Europa. O próprio critério de classe tende a ser secundarizado para pensar as ex-colônias. Ambos supõem uma abstrata comunidade de interesses - ideológica para os subalternistas; a "comunidade de interesses raciais" para Quijano (Ibid.: 18) - entre as classes burguesas e populares na Europa. Resulta daí que a singularização do capitalismo periférico implica, nos dois casos, em romantização do desenvolvimento capitalista central.

Resta comparar racialidade e subalternidade em relação a dois aspectos evidenciados por Chibber ao ler os Subaltern Studies: B) o dualismo consenso $x$ coerção nas relações de trabalho; C) o dualismo princípio de interesse $x$ princípio 
de comunidade. Quijano também as supõe ao especificar a experiência latinoamericana?

B) Vimos como Chakrabarty atribuirá à dominância sem begemonia da burguesia indiana a "falha" do capital em adquirir supremacia na transformação das relações de poder naquele país. Devido a esta "falha" haveria capitalismo na Índia, mas sem suas "formas burguesas", "dominação capitalista sem uma cultura capitalista hegemônica". As formas paternalistas de dominação, coercitivas e interpessoais, teriam primado sobre a relação-capital nas relações de trabalho. Por isso a esterilidade de conceitos que pensam a exploração capitalista na Europa, fundada no consenso capital-trabalho.

Quijano (2002) lucidamente estabelece a distinção entre uma proposição teórica abstrata da relação-capital e a aplicação histórica deste esquema teórico. $\mathrm{Na}$ pureza, a relação-capital é corretamente definida como "uma forma específica de controle do trabalho que consiste na mercantilização da força de trabalho a ser explorada", ou seja, no assalariamento. "Por sua condição dominante em tal conjunto estrutural [capitalismo], outorga a esse [ao assalariamento] seu caráter central - quer dizer, o faz capitalista - mas historicamente não existe, não existiu nunca e não é provável que exista no futuro, separado ou independentemente das outras formas de exploração". "Tais formas de controle do trabalho se articularam como estrutura conjunta em torno do predomínio da forma salarial, chamada capital, para produzir mercadorias para o mercado mundial" (Idem, 2005: 5).

Quijano se distancia dos subalternistas nesse aspecto. Não é por haver sobredeterminação de formas de dominação (poder) orientadas para a produção de valor (capital) que se pode negar a importância da definição abstrata de relação-capital, e das categorias da crítica da economia política para entender os processos de trabalho no mundo periférico. A generalidade da teoria não pode e não precisa ser idêntica à concretude histórica. A sobredeterminação capital-poder não é evidência suficiente para negar a teoria marxiana do capital, pois trata-se, como já foi dito, de uma articulação de formas de trabalho historicamente pré-capitalistas à estrutura do capitalismo via circulação global de mercadorias. 
N'outro momento do texto citado nos parágrafos anteriores, ao tratar de um conjunto de dados que confirmam uma tendência crescente à polarização social, à concentração de riquezas, à articulação de formas de exploração, ao incremento do desemprego estrutural e à precarização do emprego em tempos de globalização, Quijano consegue deixar ainda mais claro a importância que confere à crítica da economia política, e a estranheza de um arbitrário divórcio entre exploração (capital) e dominação (poder) sem atentar para o caráter sobredeterminado da articulação capital-poder na estrutura capitalista.

Nenhuma de todas essas tendências é nova ou imprevista... Indicam um momento, um grau ou um nível da maturação e do desenvolvimento de tendências inerentes ao caráter do capitalismo como padrão global de controle do trabalho e que tinham sido longamente teorizadas, sobretudo, desde Marx (Ibid.: 9)

C) Vimos como, por vias diferentes, Quijano e os autores indianos criticados por Chibber chegam a uma imagem das formações nacionais periféricas onde se vê um imenso abismo entre elites e subalternos. Abismo tal que democracia e cidadania seriam valores ausentes para a massa subalterna. Vimos também que, para os subalternistas indianos, a subalternidade indiana continuaria presa a valores tradicionalistas, religiosos, onde individualidade e interesse não teriam terreno fértil para se desenvolver, e as mobilizações políticas teriam, em última análise, um caráter comunal, e não de classe. E para Quijano, quais seriam as características da subalternidade produzida pela colonialidade do poder na periferia latino-americana?

"A comunidade e a associação de comunidades como a estrutura institucional de autoridade pública, local e regional", é, para Quijano (Ibid.: 18), o horizonte emancipatório que poderá superar as contradições do Estado-nação pretensamente democrático, mas enraizado na não-resolução do problema da colonialidade do poder. Nessa utopia, a comunidade seria a célula capaz de concretizar os ideais 
democráticos de igualdade social (para além da igualdade de poder se vender no mercado), liberdade individual e solidariedade social. O princípio fundamental da comunidade seria a "reciprocidade como forma de organização do trabalho e de distribuição democrática de seus recursos e de seus produtos" (Ibid.: 26). Um tipo de regulação que não passe pela institucionalidade estatal.

Quijano tem uma concepção complexa e original de comunidade e reciprocidade. Para ser mais preciso, para ele, comunidade e reciprocidade ganham contornos novos na medida em que se articulam aos processos típicos da modernidade/colonialidade. Encontraremos este desenvolvimento dos conceitos em texto de Quijano publicado originalmente em 1998, Del "Polo Marginal" a la "Economia Alternativa", onde analisa as organizações econômicas populares (OEP) em países latino-americanos (principalmente Chile e Peru). Organizações de segmentos marginalizados que se definem por relações de tipo "comunais", de ajuda mútua, tendentes a se dar fora do mercado.

Primeiramente, Quijano (2014e: 229) nega a tese de Luís Razeto sobre a formação de uma "economia alternativa" a partir das OEPs. Para ele, poderíamos falar da existência paralela de uma "economia popular", protagonizada por aqueles "que não controlam os recursos principais de produção, nem as alavancas do poder estatal, ou aquelas do mercado", e onde existe uma "variável combinação entre padrões do capital e de reciprocidade". No entanto, "o predomínio tendencial dos primeiros" impede que possamos falar de uma "economia alternativa". Trata-se, antes, de experiências que devem ser amadurecidas, no sentido da utopia anteriormente referida de uma "associação de comunidades como a estrutura institucional de autoridade pública, local e regional".

Importa nesse contexto colocar em plano primeiro a definição de reciprocidade plena como "relações de produção/distribuição" de produtos e força de trabalho de caráter "direto", sem o intermédio do mercado, "entre sujeitos socialmente iguais". E, principalmente, a definição de comunidade plena como "modo de organização coletiva onde todos os membros individualmente se consideram socialmente iguais, intervêm diretamente nas decisões, através dos debates e de 
um sistema de autoridades elegidas e controladas de modo imediato e direto" (Ibid.: 229).

Se, de fato, Quijano (Ibid.: 230-1) admite, comunidade e reciprocidade foram princípios centrais na organização da vida dos povos que ocupavam o território americano antes do século XVI, tais princípios adquirem um caráter de novidade sociológica na sociedade contemporânea, na medida em que adquirem caráter urbano e por seus traços singulares. Quijano sintetiza as diferenças entre a comunidadereciprocidade pré-colonial - típica de "coletividades fechadas, onde a hierarquia social e a tradição eram a fonte das normas e dos valores cotidianos, e onde, por outro lado, o espaço de identidade e de liberdade individuais" era restringido - e a comunidade-reciprocidade contemporânea - alimentada pela "identidade e criatividade dos indivíduos", onde predomina a "mudança" e não a "continuidade" como lugar de resistência anti-capitalista.

Marcam-se assim as diferenças da concepção quijaniana e subalternista de comunidade subalterna. Em Quijano não há recaída numa exoticização orientalista e num dualismo de princípios psicológicos Norte/Sul, Oeste/Leste. A racionalização individual não aparece como atributo exclusivo do Norte/Oeste. A nova comunidade surge como híbrido de valores tradicionais de solidariedade e reciprocidade, e valores modernos, societários, de autonomia, individualidade e escolha. A motivação para a formação deste tipo novo de comunidade, não-tradicionalista, voltada para o futuro, é primeiramente, um interesse de ajuda mútua diante de necessidades materiais não supridas. Deste modo, Quijano está muito mais próximo de Chibber, que percebe como motivação primeira para a organização política das classes subalternas o interesse básico de manutenção ou conquista do bem-estar.

\section{CONCLUSÃO}

Pode-se dizer que tanto o trabalho de Quijano como o dos primeiros subalternistas é fundamental nos três aspectos aqui tratados: 1) atenta para a necessidade de uma análise da forma histórica de desenvolvimento 
capitalista na periferia, rejeitando a violência teoricista do universal sobre o singular; 2) atenta para as formas particulares de configuração da relaçãocapital em diferentes contextos históricos, políticos e culturais; 3) chama a atenção para a heterogeneidade de formas de ação dos grupos subalternos, para além de um modelo rígido de ação política de classe.

No entanto, a ênfase na diferença pode tender ao dualismo e, em última análise a uma romantização essencialista do que seria a formação clássica do capitalismo e dos Estados nos países ditos centrais. Tomamos a crítica de Vivek Chibber (2013) aos subalternistas como um ponto de partida, por um lado, precisamente pelo esforço, por vezes exagerado, em evidenciar e evitar aquelas tendências. Se há uma clara afinidade entre o dualismo comunidade de interesses raciais/ cisão racial em Quijano e o dualismo dominância hegemônica/dominância sem hegemonia nos estudos subalternos, Quijano não chega a tornar rigidamente dual capital-consenso/poder-coerção, nem princípio de interesse/princípio comunal, pensando de forma dialética as singularidades da universalização do capital e as heterogeneidades políticas daí decorrentes.

Por outro lado, ao desconstruir o mito da burguesia hegemônica europeia, ao buscar demonstrar a forma específica de manifestação do poder coercitivo nos países desenvolvidos, ao buscar pensar os atributos de autonomia, individualidade, interesse como generalizáveis a toda cultura humana, Chibber instiga o pensamento. Na esteira da sua reflexão também poderíamos perguntar se princípios comunais (não-seculares) também não são uma força de mobilização política fundamental nos países centrais. Qual é o peso da religião e do mito em geral, assim como da ideia de dever e comunidade na política dita Ocidental?

No caso do dualismo estabelecido pela colonialidade do poder/ racialidade: É correto pensar a racialidade como fenômeno ausente nos países centrais? O que pensar, por exemplo, das lutas raciais nos EUA ou do 'problema migratório' na maioria dos países desenvolvidos? Como pensar o desenvolvimento dos países centrais mesmo diante da forte presença da cisão racial? 
Estas nos parecem questões importantes que só podem ser respondidas com a superação dos constrangimentos impostos pelo pensamento dualista.

\section{BIBLIOGRAFIA}

ASTON, T. H.; PHILPIN, H. E. (eds.). The Brenner Debate. Cambridge: Cambridge University Press, 1985.

BALLESTRIN, Luciana. América Latina e o giro decolonial. In: Revista Brasileira de Ciência Política, n. 11. Brasília, pp. 89-117, maio-agosto de 2013.

BRENNER, R. Merchants and Revolution. Princeton: Princeton University Press, 1993.

CHAKRABARTY, D. Provincializing Europe. Princeton: Princeton University

Press, 2007.

- Rethinking working-class history: Bengal 1890-1940. Princeton: Princeton University press, 1989.

CHATTERJEE, P. Nationalist thought and the colonial world: a derivative discourse?. London: Zed Press, 1986.

CHIBBER, Vivek. Postcolonial theory and the specter of capital. London: Verso, 2013.

. Capitalism, class and universalism. In: Socialist Register, v. 50, 2014.

CONNEL, Raewyn. Southern theory: the global dynamics of knowledge in social science. Cambridge: Polity Press, 2007.

GUHA, R. On some aspects of the historiography of colonial India. In: GUHA (ed.). Subaltern Studies I: Writings on South Asian History \& Society. Delhi: Oxford University Press, 1982. 
- Elementary Aspects of peasant insurgency in colonial India. Delhi: Oxford University Press, 1983.

. Dominance without Hegemony. Cambridge: Harvard University Press, 1997.

MARX, Karl. O capital, livro I, v. 1. Rio de Janeiro: Civilização Brasileira, 2008.

QUIJANO, A. Colonialidad y Modernidad-Racionalidade. In: Bonilla, Heraclio. Los Conquistados: 1492 y la población indígena de las Américas. Bogotá: Tercer Mundo, 1992.

. El fantasma del desarrollo en América Latina. In: Rev. Venez: de Econ. y Ciencias Sociales, vol. 6 No 2 (mayo-agosto), pp. 73-90, 2000.

. Colonialidade, poder, globalização e democracia. In: Novos rumos, ano 17, n. 37, 2002.

- Colonialidade do poder, eurocentrismo e América Latina. In: Lander, Edgardo (org.). A colonialidade do saber: eurocentrismo e ciências sociais. Perspectivas latino-americanas. Colección Sur Sur. Buenos Aires: CLACSO, 2005.

- Dependencia, cambio social y urbanización en Latinoamérica. In: CLÍMACO, D (org.). Cuestiones y Horizontes: de la dependencia historico-estrutural a la colonialidad/descolonialidad del poder. Buenos Aires: CLACSO, 2014a.

. "Polo marginal" y "mano de obra marginal". In: CLÍMACO, $\mathrm{D}$ (org.). Cuestiones y Horizontes: de la dependencia historico-estrutural a la colonialidad/descolonialidad del poder. Buenos Aires: CLACSO, 2014b.

. Sobre la natureza actual de la crisis del capitalismo. CLÍMACO, $\mathrm{D}$ (org.) Cuestiones y Horizontes: de la dependencia historico-estrutural a la colonialidad/descolonialidad del poder. Buenos Aires: CLACSO, 2014c. 
- América Latina en la economía mundial. CLÍMACO, D (org.) Cuestiones y Horizontes: de la dependencia historico-estrutural a la colonialidad/ descolonialidad del poder. Buenos Aires: CLACSO, 2014d.

. Del "polo marginal" a la "economía alternativa". CLÍMACO, D (org.) Cuestiones y Horizontes: de la dependencia historico-estrutural a la colonialidad/descolonialidad del poder. Buenos Aires: CLACSO, 2014e. 
